\title{
Research on financial efficiency loss from the perspective of externality of efficiency loss of state-owned enterprises
}

\author{
Zhou Xiaohe $^{1, a}$ and Cheng Mingda ${ }^{2, b}$ \\ ${ }^{1}$ Sichuan Agricultural University, Chengdu, Sichuan, China \\ ${ }^{2}$ Zhejiang University, Hangzhou, Zhejiang, China \\ a614016390@qq.com, b2273835501@qq.com
}

\begin{abstract}
Keywords: Efficiency loss of state-owned enterprises, Externality, Financial efficiency, Nonperforming loan ratio.
\end{abstract}

\begin{abstract}
In order to explore the cumbrance effect of state-owned enterprises (SOE) on regional financial efficiency (FINC) and expand the research field of efficiency loss of SOE, this paper bases on the externality of efficiency loss, considering that the soft budget constraint caused by the policy burden of SOE would lead to the reduction of their own benefits and the financial crowding out effect on regional non-state-owned enterprises, and then reduces the efficiency of regional financial institutions. Using 31 provinces (municipalities and autonomous regions) panel data from 2006 to 2015, applying fixed effects-random effects model to verify the impact of the proportion of SOE on FINC, the results of which show that the higher the proportion of SOE is, the higher non-performing loan rate (NPLR) in the region will be. Finally, according to the above analysis, this paper puts forward corresponding policy suggestions.
\end{abstract}

\section{Introduction}

Compared with the previous years, the operating profit of enterprises is generally lower. They mainly exhibit low-yield and high-liability trends, leading to an increase in bad debts ratios of banks [1]. Financial development plays an essential role in promoting economic growth $[2,3]$. As the conduction end of corporate debt, the development of banking and financial industry is restricted by the SOE to some extent, the most direct manifestation is the NPLR of SOE to banks [4]. Although the NPLR of banks has dropped drastically after the reforms, many domestic studies have theoretically believed that SOE still shows a negative "incentive" effect on bank development. It is mainly reflected in the reduction of NPLR of SOE in the financial industry $[5,6,7]$. The high NPLR can not only hinder the development of enterprises, but also lead to the failure to supply the financial needs of private enterprises in time. Thus, it restricts the development of private enterprises and further affects the stable development of the economy. Therefore, the analysis of the causes of NPLR by financial institutions and the search for appropriate solutions are the top priorities of the current study.

Since the reform and opening up to the outside world, the reform of SOE has always been the core of economic reform and has long been valued by various economists. Comprehensive research by former scholars shows that the very low efficiency of SOE is a consensus reached by the theoretical community $[8,9,10]$. However, most papers measure the efficiency of SOE or have a direct impact on the local economy, but lack of research on "indirect effects" and "mechanism of action" [11]. In addition, SOE not only suffer loss of efficiency, but also result in the efficiency loss of other departments due to externality $[12,13,14]$.

Based on the externalities of the efficiency loss of SOE, this paper demonstrates whether SOE will lead to an increase in NPLR in the region from the perspective of finance, and to explore the research of the efficiency loss of SOE on the financial industry.

\section{Method}

\subsection{Data collection}

Based on the "China Statistical Yearbook" and "Wind" database, this paper selects the balance panel data of 31 provinces (province-level municipality) in China from 2006 to 2015 to study the drag effect 
of state-owned economy on FINC. In addition, since FINC is also affected by other factors, this paper selects other variables that may affect FINC as control variables.

Table 1. Variable Description Table

\begin{tabular}{ccc}
\hline Variable & Code & Name \\
\hline Explained & $N P L$ & Non-performing loan rate \\
\hline Explanatory & Soe & The proportion of state-owned economy \\
\hline \multirow{3}{*}{ Control } & Asg & Financial institution assets \\
\cline { 2 - 3 } & $F d i$ & Foreign investment level \\
\cline { 2 - 3 } & Gov & Government role \\
\cline { 2 - 3 } & Gdp(index $)$ & Regional economic fluctuation index \\
\cline { 2 - 3 } & Dlr & deposit loan ratio \\
\hline
\end{tabular}

\subsection{Model}

Using fixed effect-random effects model to study the effect of SOE on regional FINC, this paper divides the data of the three parts of East, Central and West separately for regression to ensure the reliability of the regression model.

$$
Y_{i t}=A+\beta_{1} * \text { Soe }_{i t}+\sum_{j}^{n} \operatorname{Con}+\alpha_{i}+\mu_{i t}
$$

$Y$ is the explanatory variable, $i$ and $t$ represent the $i$ province and the $t$ year respectively. Con represents the selected control variable, $\alpha_{i}$ is the individual effect of the region, and $\mu$ is the residual item.

\section{Empirical test and result analysis}

\subsection{Stability test}

The paper uses stata13.1 and adopts LLC test and ADF-Fisher test to perform the unit root test on existing data. The test results are shown in Table 2. Two methods of testing show that all variables reject the assumption of "existence unit root", which indicate the panel data is stable.

Table 2. Panel data unit root test results

\begin{tabular}{clccl}
\hline Variables & & LLC & ADF & Test result \\
\hline Npl & Trend item & $-85.88^{* * *}$ & $1576.82^{* * *}$ & Stationary \\
Dlr & Trend item & $-13.31 * * *$ & $225.07 * * *$ & Stationary \\
Soe & Trend item & $-10.92^{* * *}$ & $126.95 * * *$ & Stationary \\
Asg & Trend item & $-11.08^{* * *}$ & $145.25 * * *$ & Stationary \\
Gov & Trend item & $-9.48^{* * *}$ & $156.51 * * *$ & Stationary \\
Gdp & Trend item & $-86.37 * * *$ & $2234.71 * * *$ & Stationary \\
Far & Trend item & $-12.89 * * *$ & $165.80^{* * *}$ & Stationary \\
Fdi & Trend item & $-5.56 * * *$ & $97.31 * * *$ & Stationary \\
\hline
\end{tabular}

Note: Asterisks indicate the following: ${ }^{* * *} \mathrm{p}<0.01,{ }^{* *} \mathrm{p}<0.05,{ }^{*} \mathrm{p}<0.1$.

\subsection{Empirical result}

In order to avoid reciprocal causation between independent variables and dependent variable, this paper takes all the independent variables as a first-order lag. The influence of the proportion of SOE on the regional FINC as shown in table 3.

Table 3. Model regression results

\begin{tabular}{ccccc}
\hline Variables & (2) National & (3) East & (4) West & (5) Central \\
\hline \multirow{2}{*}{ L. Soe } & $0.241^{* * *}$ & $0.0807^{*}$ & $0.254^{* * *}$ & $0.290^{* *}$ \\
& $(0.0577)$ & $(0.0454))$ & $(0.0924)$ & $(0.139)$ \\
L. Dlr & $0.129^{* *}$ & -0.0343 & $0.244^{* * *}$ & $0.265^{*}$ \\
& $(0.0507)$ & $(0.0270)$ & $(0.0652)$ & $(0.157)$ \\
L. Fdi & -0.00324 & -0.00403 & $0.224^{* * *}$ & $0.394^{* * *}$ \\
& $(0.00557)$ & $(0.00353)$ & $(0.0658)$ & $(0.100)$ \\
L. Gov & 0.0654 & 0.120 & -0.0411 & -0.543 \\
& $(0.109)$ & $(0.124)$ & $(0.110)$ & $(0.454)$ \\
L. Far & -0.0222 & -0.00403 & $-0.0640^{*}$ & -0.0499 \\
& $(0.0240)$ & $(0.00353)$ & $(0.0341)$ & $(0.0499)$
\end{tabular}




\begin{tabular}{ccccc} 
& $-0.0212^{* *}$ & $-0.00813^{* *}$ & $-0.0552^{* * *}$ & $-0.0836^{*}$ \\
L. Asg & $(0.00929)$ & $(0.00388)$ & $(0.0143)$ & $(0.0473)$ \\
L. Gdp & $0.363 * * *$ & $0.276^{* *}$ & 0.0241 & -0.585 \\
& $(0.138)$ & $(0.133)$ & $(0.204)$ & $(0.449)$ \\
Constant & $-0.139 * * *$ & 0.00924 & $-0.158^{* *}$ & -0.0277 \\
$\mathrm{R}^{2}$ (within) & $(0.0461)$ & $(0.0295)$ & $(0.0646)$ & $(0.117)$ \\
$\mathrm{R}^{2}$ (between) & 0.258 & 0.1729 & 0.4786 & 0.4594 \\
$\mathrm{R}^{2}$ (overall) & 0.114 & 0.2146 & 0.0191 & 0.1560 \\
$\mathrm{~F}$ & 0.083 & 0.1705 & 0.1167 & 0.1204 \\
Wald(p) & 11.95 & 18.71 & 11.67 & 6.92 \\
Hausman Test & 0.0000 & 0.0091 & 0.0000 & 0.0000 \\
Model & $21.87(0.0027)$ & $5.20(0.6359)$ & $31.67(0.0000)$ & $19.47(0.0068)$ \\
\hline Standard errors appear in parentheses. Asterisks indicate the following: ***p<0.01, **p $<0.05, * \mathrm{p}<0.1$.
\end{tabular}

According to the regression results of model (2) to model (5), it is shown that Soe has a significant positive correlation with $\mathrm{Npl}$, which shows that the proportion of SOE does have a positive effect on the increase in NPLR in the region and distorts the FINC. In terms of control variables, Dlr has a significant positive effect on $\mathrm{Npl}$. It indicates that excessive deposit loan ratio will lead to a decline in the ability to resist risks. Asg has a negative effect on $\mathrm{Npl}$, which indicates that increasing assets of the banks will increase the prudence in investment. Except for the significant positive correlation of Gdp(index), all other control variables are not significant. The phenomenon is speculated that financial institutions will have a certain expectation of macroeconomic changes and will take certain measures to avoid risks.

Models (3) to (5) are the results of the regression of the data for the three regions of the East, West and Central respectively. The proportion of SOE in the three models is positively correlated with the NPLR in the region, indicating that the regression results are relatively stable. In addition, the regression coefficient in the Midwest is significantly higher than that in the East. This paper argues that the Eastern region has a relatively developed economy, a strong industrial base and complete supporting policies, and both number and strength of private enterprises are higher than the other two regions. Therefore, the FINC loss caused by SOE will be alleviated due to the high efficiency and economic vitality of private enterprises.

\section{Conclusion and suggestion}

\subsection{Conclusion}

The main conclusions of the paper are as follows. 1. SOE will have their benefits reduced due to soft budget constraints, financial crowding out effects as well as exclusion of non-state-owned enterprises in the region, leading to distortions and reductions in the allocation of funds to regional financial institutions. The effect shows that with the increase in the proportion of SOE in the region, the NPLR has risen, which would lead to a drag effect on the FINC of the region. Therefore, the policy burden is the root cause of soft budget and financial crowding out. 2. The degree of influence of SOE in different regions on FINC is different. SOE in the East has less impact on FINC than SOE in the Midwest. It shows that economy, enterprise innovation and institutional environment can alleviate the distortion of FINC of SOE.

\subsection{Suggestion}

\subsubsection{Reduce the policy burden of SOE}

The policy burden of SOE is the root cause of the decline in their own efforts and indirect FINC. Therefore, local governments should take certain measures to appropriately reduce the reliance on SOE to achieve social goals. This can effectively improve the operating efficiency of SOE and reduce their drag on FINC.

4.2.2 Improve the market competition environment of SOE.

In order to reduce the impact of SOE on the FINC, it is necessary to have a fair market competition environment. On the one hand, local governments should reduce the policy support and monopoly 
protection of SOE so as to promote the efficiency and competitiveness of SOE. Moreover, the regulatory authorities should reduce the administrative interference in the management design of SOE and make a reasonable incentive system according to the operating conditions of SOE.

\section{Reference}

[1] Feng Fei, Reflections on establishing a new relationship between banks and enterprises: The state-owned enterprises to explore and excessive debt problem banks non-performing assets, Journal of Civil Aviation University of China, (S1), pp. 211-215, 2004.

[2] R Levine, Finance and growth: Theory and evidence, Social Science Electronic Publishing, 1(05), pp. 37-40, 2004.

[3] T Beck, R Levine, N Loayza, Finance and the source of growth, Journal of Financial Economics, 58(1), pp. 261-300, 2001.

[4] Zheng Quan, Solve the problem of debt between state-owned enterprises and banks at different levels, South China Finance, (04), pp. 33-35, 1995.

[5] H. Wang. Endogenous mechanism and periodicity of non-performing loans in commercial banks: Based on game theory of government, banks and state-owned enterprises, Contemporary Finance \& Economics, (01), pp.50-59, 2017.

[6] Q. Xin and Lin Bin, Debt leverage and corporate investment: Double budget soft constraints perspective, Journal of Finance and Economics, (07), pp.73-83, 2006.

[7] H. Shi, Endogenous non-performing loans of state-owned commercial banks in China: An analytical framework based on double soft budget constraint, Journal of Financial Research, (06), pp.1-16, 2004.

[8] Megginson W L, Netter J M, From state to market: A survey of empirical studies on privatization[J]. Journal of Economic Literature, 39(2), pp.321-389, 2001.

[9] N Boubakri, JC Cosset, The financial and operating performance of newly privatized firms: Evidence from developing countries, The Journal of Finance, 53(3), pp.1081-1110, 1998.

[10]RL Porta, The benefits of privatization: Evidence from Mexico, Quarterly Journal of Economics, 114(4), pp.1193-1242, 1999.

[11]R. Liu, State-owned enterprises efficiency in China: A literature review, The Journal of World Economy, (11), pp.136-160, 2013.

[12]R. Liu and Shi Lei, Double efficiency losses and economic growth of state-owned enterprises, Economic Research Journal, (1), pp.127-137, 2010.

[13]R. Liu, Financial repression, ownership discrimination and growth drag: Review of the efficiency loss of state-owned enterprises, China Economic Quarterly, 10(1), pp.603-618, 2011.

[14]R. Liu, State-owned enterprises, implicit subsidies and market segmentation: Theoretical and empirical evidence, Management World, (4), pp.21-32, 2012. 